\title{
D.C. SPUTTERING PROCESS: ITS CHARACTERIZATION AND ITS PROBLEMS WHEN APPLIED TO TIN-DIOXIDE THIN-FILMS
}

\author{
ANANT G. SABNIS \\ Department of Electrical Engineering, University of Pittsburgh, Pittsburgh, PA 15261. U.S.A \\ (Received April 11, 1979)
}

\begin{abstract}
This paper discusses the problems involved in obtaining reliable and reproducible thin films of Sb-doped $\mathrm{SnO}_{2}$ films by the d.c. sputtering process. An attempt to characterize the process is made by correlating the deposition parameters with the factors that contribute to the conductivity of the $\mathrm{SnO}_{2}$ films. The areas of concern are identified, and guidelines are offered for making the process and the film properties controllable.
\end{abstract}

\section{INTRODUCTION}

Although the transparent tin dioxide $\left(\mathrm{SnO}_{2}\right)$ films when deposited by chemical vapor deposition methods ${ }^{1}$ can behighly conductive $\left(\sim 10^{4} \Omega^{-1} \mathrm{~cm}^{-1}\right)$, they may not be adequately conductive $\left(<500 \Omega^{-1} \mathrm{~cm}^{-1}\right)$ when deposited by d.c. sputtering process. ${ }^{2}$ The author has attempted to investigate the various problems associated with the $\mathrm{SnO}_{2}$ films and the sputtering process. The discussion is specifically centered around the $\mathrm{Sb}$-doped $\mathrm{SnO}_{2}$ films and the d.c. glow discharge sputtering process. It is hoped that the material presented here will be useful in evaluating $\mathrm{SnO}_{2}$ and the sputtering process for device applications; and that it will stimulate interest for future research in this field.

The d.c. glow discharge sputtering, hereafter referred to as "sputtering", is characterized with an objective of relating the deposition parameters to the properties of the $\mathrm{Sb}$-doped $\mathrm{SnO}_{2}$ films, henceforth referred to as "the films". This should enable one to understand how to control the conductivity and the transparency of the films and obtain reproducible films run after run.

\section{THE SPUTTERING PROCESS AND THE FILMS}

This process is very complex in nature due to the basic physics of the process and the interpretation of the results is further complicated by the properties of the sputtered films depending on several deposition parameters. The various deposition parameters can be listed as: (1) sputter gas, (2) gas pressure, (3) gas flow rate, (4) electrode dimensions, (5) electrode spacings, (6) electrode voltage, (7) discharge current, (8) substrate material, (9) substrate temperature, (10) target material composition, (11) target density, and (12) target temperature.

It is generally believed that if all these parameters are kept constant from run to run, one should be able to obtain reproducible films. There are several difficulties, however, which arise in maintaining identical deposition conditions from run to run. Hence reproducibility of the films becomes hard to achieve.

Even if the process parameters were kept identical in each run, the films may not necessarily be reproducible at least as far as the electrical conductivity is concerned. The conductivity of the films is attributed to: (a) the interstitial tin, (b) oxygen deficiencies, and (c) the $\mathrm{Sb}$ content. The other factors which affect the film conductivity are: (d) the film thickness, (e) the surface roughness, (f) the grain size, and $(\mathrm{g})$ the film contamination during sputtering.

The complexity of the process of obtaining reproducible films now becomes evident. The conductivity can be controlled effectively by controlling the factors that contribute to it or affect it. Such control may be possible by proper manipulation of the process parameters. This necessitates an understanding of the influence of the deposition parameters on the various factors that determine the film conductivity. 


\section{EFFECT OF DEPOSITION PARAMETERS ON THE FILM CONDUCTIVITY}

The films deposited in argon (Ar) have been observed to be more conductive than those deposited in nitrogen (or air or oxygen). ${ }^{3}$ The films sputtered in Ar tend to be deficient in oxygen to an extent that under certain deposition conditions the films become opaque. ${ }^{2}$ The target surface also turns grey in color which is indicative of reduction of surface. With increasing oxygen deficiency the films become more conductive and at the same time, they become less transparent. Hence, control of conductivity via oxygen deficiency requires a compromise of the transparency.

The other parameters that influence the oxygen deficiency are the gas flow rate and the target density. The continuous flow of sputter gas tends to sweep out the oxygen ions from the interelectrode space, and increasing oxygen deficiency in the film occurs as the flow rate is increased. The targets which are porous, are less efficient in heat dissipation. Therefore, the surface from which actual sputtering occurs is at a higher temperature than its back surface. Consequently, the target surface tends to become reduced, and in turn makes the films more deficient in oxygen.

Introducing oxygen deficiencies is not an effective method of controlling the film conductivity due to the lack of control over the concentration of the oxygen deficiencies. Although the films may be sputtered in Ar because it yields higher deposition rates than other gases, it seems advisable to make the targets as dense as possible and maintain mild rates of the gas flow in the system. Otherwise, opaque films may result which will need a second step of oxidation in the oxidizing atmosphere. ${ }^{4}$

Along with the oxygen deficiencies, the other factor that contributes to the film conductivity is the tin interstitials. These two factors may be slightly interrelated and are equally uncontrollable. Therefore, for the sake of reproducibility the contribution to the conductivity by these factors should be maintained as small as possible.

The third factor which contributes to the film conductivity is the antimony content of the film. The $\mathrm{Sb}$ is most effective when it substitutionally replaces $\mathrm{Sn}$ atoms. Interstitial $\mathrm{Sb}$ tends to distort the crystal structure and makes the films more resistive. The $\mathrm{Sb}$-contents of the films and of the targets are correlated. Therefore, it seems possible to control the film conductivity by controlling Sb-content in the film. This necessitates the knowledge of the

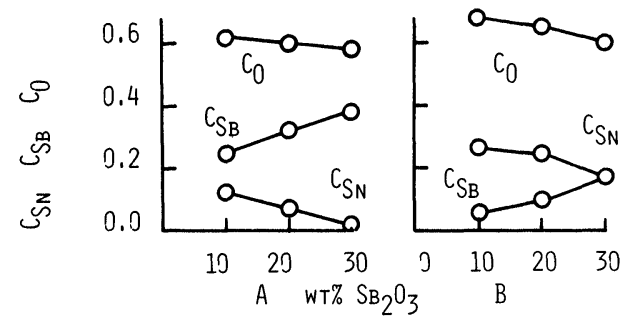

FIGURE 1 Relative concentrations $\mathrm{C}_{\mathrm{Sb}}, \mathrm{C}_{\mathrm{Sn}}$, and $\mathrm{C}_{\mathrm{O}}$ of $\mathrm{Sb}, \mathrm{Sn}$ and $\mathrm{O}$, respectively, $\mathrm{A}$ at the target surface, $\mathrm{B}$ in the film as a function of percent $\mathrm{Sb}_{2} \mathrm{O}_{3}$ in the starting mix ture of the target.

correspondence between the two Sb-contents. It has been observed that the relative concentration of $\mathrm{Sb}$ in the films is less than that at the surface of the target; ${ }^{5}$ and that the dependence of one over the other is not necessarily linear. It is also probable that such a correspondence could depend on the other deposition parameters such as substrate temperature, gas flow rate and the target density. Nevertheless, it is possible to establish the relation between the two $\mathrm{Sb}$-contents for a given set of deposition parameters; and that can be used as a guide for predicting the film conductivity. The correspondence between the Sb-contents of the films and the targets for a fixed set of deposition parameters ${ }^{5}$ is shown in Figure 1.

An effective use of the correlation between the $\mathrm{Sb}$-contents can be made in predicting the film conductivity provided the Sb-content within the target is uniformly distributed. Such a uniformity is hardly likely unless the targets are carefully fabricated. It is a general practice to fabricate targets by mixing the $\mathrm{SnO}_{2}$ and $\mathrm{Sb}$ (or $\mathrm{Sb}_{2} \mathrm{O}_{3}$ ) powders together well in electromechanical shakers for 24 to 30 hours, and then by compressing this powder to form circular discs, which finally are sintered in special furnaces. The distribution of Sb will certainly depend on the homogeneity of the mixture, the sintering temperature, and the duration of sintering. In Figure 2 are shown the relative concentrations of $\mathrm{Sn}, \mathrm{O}$, and $\mathrm{Sb}$ in the targets which were fabricated following the procedure described above. The starting mixture of $\mathrm{SnO}_{2} 90 \%$ and $\mathrm{Sb} 10 \%$ by weight was used, and the targets were sintered for different lengths of time $(2 \mathrm{~h}, 3 \mathrm{~h}, 4 \mathrm{~h})$. The representative results of the Auger analysis shown in Figure 2 indicate that the $\mathrm{Sb}$ distribution becomes uniform after four hours of sintering. The relative concentrations near the surface of the target on which the targets rested in the furnace during sintering are obviously distorted. Therefore, it is recommended 


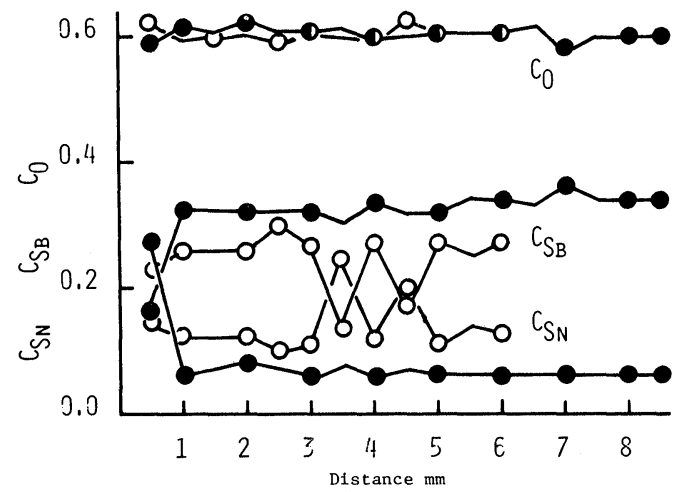

FIGURE 2 Relative concentrations of $\mathrm{Sn}, \mathrm{Sb}$ and $\mathrm{O}$ along the axis of the target. Concentrations are determined at $1 / 2$ $\mathrm{mm}$ interval. Open circles $-2 \mathrm{~h}$ and solid circles $-4 \mathrm{~h}$ sintering.

that the sputtering be carried out from the surface which is exposed to ambient in the furnace during sintering as it can be seen that the target composition there is uniform. It should be noted that the concentrations are not absolute values but are relative concentrations. The details of the analysis of the targets and the films will be a topic of a future publication. ${ }^{6}$

The density of the targets thus formed is generally somewhere between $70 \%$ and $90 \%$ of the solid density of $\mathrm{SnO}_{2}$. The heat dissipation from such targets is usually poor, consequently a temperature gradient is established across the two surfaces of the target, the one from which sputtering takes place and the other which is in contact with the cooling reservoir. Because of this gradient the $\mathrm{Sb}$ tends to migrate toward the hotter surface, which causes a build-up of $\mathrm{Sb}$ at the sputtering surface of the target. This phenomenon can significantly affect the properties of the films. To avoid this, the targets should be made as thin and as dense as possible.

The type of the substrate can have an appreciable effect on the film conductivity if the deposition temperature is low $\left(30^{\circ} \mathrm{C}\right) .^{3}$ The conductivities of the films deposited under identical deposition conditions on glass and ceramic substrates are listed in Table I. The films on the glass substrates are more conductive than those on the ceramic substrates. At higher deposition temperatures, however, the conductivity becomes insensitive to the material of substrate. ${ }^{7}$ The substrate temperature is a very important deposition parameter that must be carefully controlled. It should be low enough to avoid deleterious effects on the other elements of the device, but it should be high enough to render film-
TABLE I

Film conductivities on glass and ceramic substrates.

\begin{tabular}{lll}
\hline$\% \mathrm{Sb}$ & $\begin{array}{l}\text { Ceramic } \\
\Omega^{-1} \mathrm{~cm}^{-1}\end{array}$ & $\begin{array}{l}\text { Glass } \\
\Omega^{-1} \mathrm{~cm}^{-1}\end{array}$ \\
\hline 0 & $5.5 \times 10^{-5}$ & $3.2 \times 10^{-5}$ \\
2 & $6.3 \times 10^{-5}$ & $1.0 \times 10^{-4}$ \\
5 & $6.5 \times 10^{-5}$ & 0.43 \\
7 & $1.5 \times 10^{-3}$ & 1.0 \\
\hline
\end{tabular}

When the substrate temperature is low $\left(30-60^{\circ} \mathrm{C}\right)$ the film conductivity is greater on glass substrates than on ceramic substrates. The films were deposited under identical conditions for different Sb-doping levels.

conductivity insensitive to the substrate material and also make the grain size larger. The films deposited at $30^{\circ} \mathrm{C}$ have small grain size and they tend to be highly resistive and unstable. ${ }^{3}$ These films, when subjected to several temperature cycles $\left(<370^{\circ} \mathrm{C}\right)$ become stable and highly conductive. ${ }^{8}$ This is probably due to the enlarged grain-size and increased substitution of $\mathrm{Sn}$ atoms by otherwise interstitial $\mathrm{Sb}$ atoms. Although the temperature cycling can be combined with other annealing processes which are normally employed in IC manufacture, the two-step nature of the process may not be highly desirable. However, the films deposited at temperatures as low as $200^{\circ} \mathrm{C}$ can be considerably stable, ${ }^{7}$ and their conductivity can be manipulated through deposition parameters. ${ }^{2}$

It should be realized that the substrate tempeature may not necessarily remain constant during sputtering. As the sputtering proceeds, the substrate temperature begins to rise from its initial value, $T o$, to a final value $\mathrm{T}$, in a characteristic time, $\tau$. If this time, $\tau$, is negligibly small compared to the total sputtering duration, $t$, then one may consider

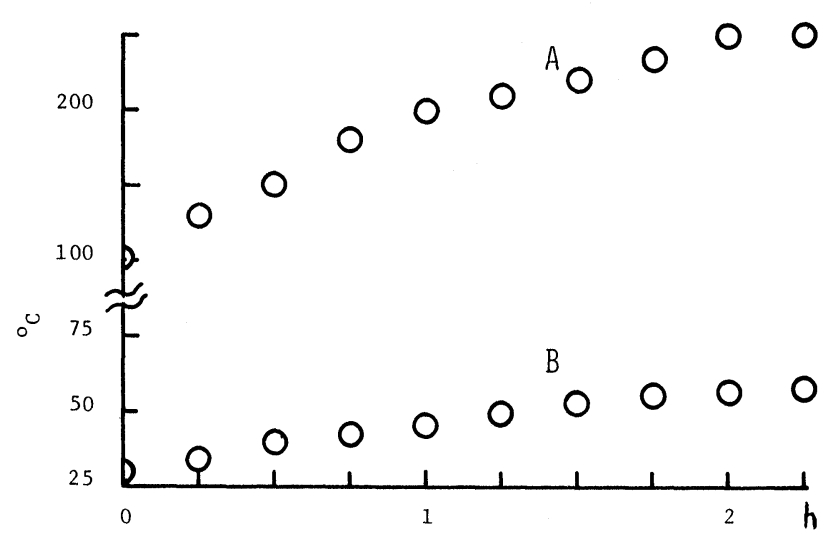

FIGURE 3 Substrate temperature increase as sputtering proceeds with sputtering power A 300 watts and B 10 watts. 
the substrate temperature to be constant. When $\tau$ is comparable to $t$, the substrate temperature cannot be considered constant, and uncertainties in the filmconductivity could arise. If the substrate temperature is not properly controlled, it will vary with time as shown in Figure 3.

When the films are very thin, the scattering of carriers at the surface can reduce the conductivity. The dependence of the conductivity on the film thickness has been observed to diminish in films thicker than $100 \mathrm{~nm}$.

\section{CONCLUSION}

This paper briefly discusses some of the problems incurred in achieving reliable and reproducible thin films of tin dioxide. An attempt is made to relate deposition parameters with the film conductivity. In conclusion, it can be stated that if the film conductivity is made to depend more on Sb-content and less on tin interstitials and oxygen deficiencies, by sputtering very dense and homogeneous targets in Ar gas, and depositing films at substrate temperatures around $200^{\circ} \mathrm{C}$, whilst maintaining a low gas flow rate, then it should be possible to obtain reproducible films run after run, depending upon how well the deposition parameters are controlled.

\section{REFERENCES}

1. V. K. Miloslavskii, Infrared Absorption of Thin Films of Tin Dioxide, Opt. and Spectrosc. VII, 2 (August 1959), $154-156$.

2. A. G. Sabnis, Preliminary Results of Metal- $\mathrm{SnO}_{2}: \mathrm{Sb}-$ Metal Type Devices, Proc. Int. Nat. Conf. Thin and Thick Films. Augsburg, W. Germany (September 1977), $258-261$.

3. A. G. Sabnis, and L. D. Feisel, Tin Dioxide Films Prepared by d.c. Sputtering from a Pressed Powder Target, J. Vac. Sci. Technol., 14, 2 (Mar/Apr. 1977), 685-689.

4. A. G. Sabnis, Two Step Process for Thin Films of Tin Dioxide, J. Vac. Sci. Technol., 15, 4 (Jul/Aug. 1978), 1565-1567.

5. A. G. Sabnis, and A. G. Moldovan, Correspondence between the Antimony Contents of the Sputtered Films and the Targets, Appl. Phys. Lett., 33, 10 (15 Nov. 1978), $885-886$.

6. A. G. Sabnis, and A. G. Moldovan, to be published.

7. A. G. Sabnis and K. Y. Chang, Effect of Substrate Temperature on D.C. Sputtered Antimony-Doped Tin Dioxide Films, Electronics Lett. (IEE England), 13, 4 (17 Feb. 1977), 113-114.

8. A. G. Sabnis, and L. D. Feisel, Heat Treatment of DC-Sputtered Tin Dioxide Thin Films, IEEE Trans. Parts, Hybrids, and Packag. PHP.-12, 4 (Dec. 1976), 357-360. 

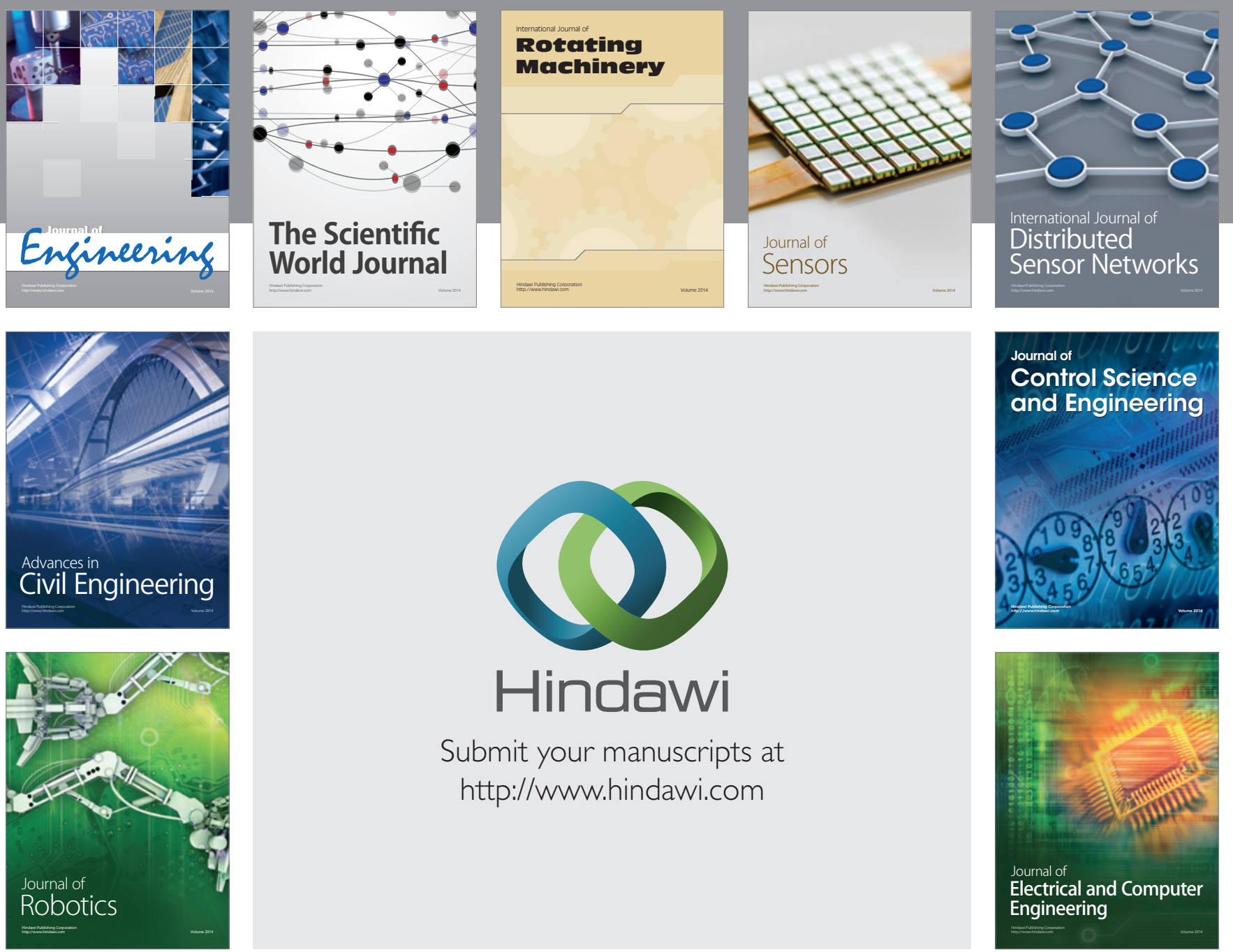

Submit your manuscripts at

http://www.hindawi.com
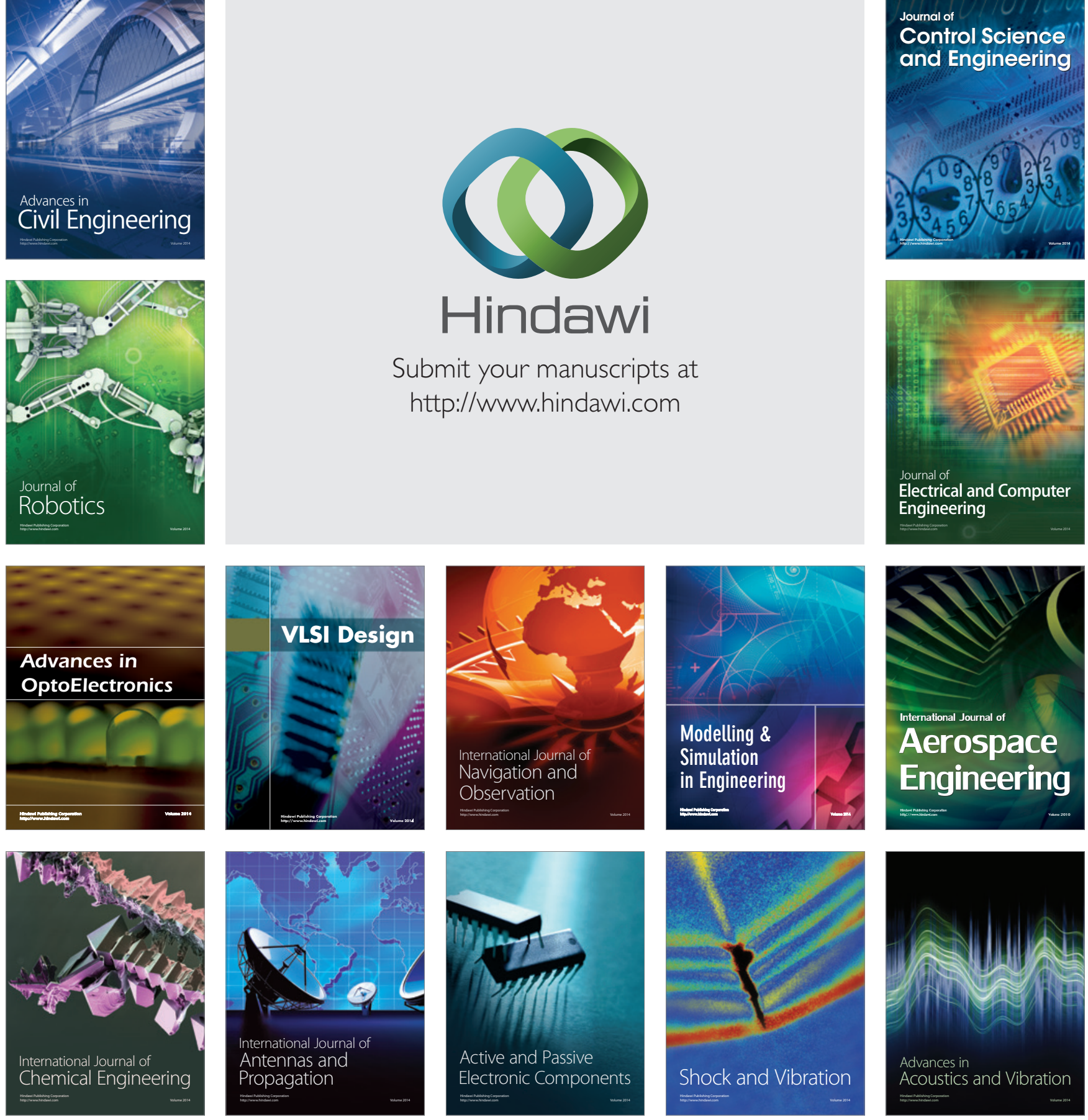